\title{
Web Currículo: implicações das tecnologias digitais na aprendizagem
}

\author{
Marlusa Benedetti da Rosa* \\ Léa da Cruz Fagundes* \\ Marcus Vinicius de Azevedo Basso ${ }^{* * *}$
}

Resumo: O presente trabalho é parte da pesquisa de doutorado na área da informática na educação que propõe, mediante um estudo experimental, gerar indicadores para a constituição de um modelo curricular que integra a tecnologia digital na educação básica, denominando-o de Web Currículo. O estudo se realiza numa escola federal de educação básica participante do Projeto UCA. Neste artigo, apresenta-se o entendimento que se tem de Web Currículo e, utilizando como metodologia a observação participante e o estudo de caso, analisa-se como as tecnologias digitais colaboram para o planejamento, desenvolvimento e acompanhamento dos projetos de iniciação científica.

Palavras-chave: Web currículo; Inclusão digital; Iniciação científica; Laptop educacional.

* Professora do Colégio de Aplicação (UFRGS) e Pesquisadora no Laboratório de Estudos Cognitivos (LEC/UFRGS), Mestre em Educação em Ciências e Matemática(PUCRS). Doutoranda em Informática na Educação(UFRGS), E-mail: marlusa.benedetti@ufrgs.br

* Professora do Programa de Pós Graduação Informática na Educação (UFRGS), Coordenadora de pesquisa no Laboratório de Estudos Cognitivos (LEC/UFRGS). Graduada em Pedagogia e Psicologia (UFRGS), Mestre em Educação (UFRGS), Doutora em Ciências-Psicologia (USP). E-mail: leafagun@ufrgs.br

*** Professor do Instituto de Matemática - (IM/UFRGS) e do Programa de Pós-Graduação em Ensino de Matemática (PPGEMAT/UFRGS), Pesquisador no Laboratório de Estudos Cognitivos. Graduado em Matemática (UFRGS), Mestre em Psicologia do Desenvolvimento (UFRGS), Doutor em Informática na Educação (UFRGS), (LEC/UFRGS) E-mail: mbasso@ufrgs.br 


\begin{abstract}
This work is part of doctoral research in area of information technology in education by proposing an experimental study to generate indicators for the establishment of a curriculum model that integrates digital technology in basic education calling it Web Curriculum. The study is being performed in a federal school of basic education which is included in UCA project. The aim of this article is to present an understanding of Web Curriculum and methodologies used such participant observation and case study, digital technologies are evaluated in perspective of how they can collaborate in planning, development and accompaniment of projects of scientific initiation.
\end{abstract}

Keywords: Curriculum web; Digital inclusion; Educational laptop; Scientific initiation.

\title{
Introdução
}

A imersão da escola na cultura digital oportunizada pela chegada dos laptops educacionais referentes ao Projeto Um Computador por Aluno ${ }^{1}$ se constitui como um espaço experimental para o desenvolvimento de propostas curriculares diferenciadas. A portabilidade do equipamento possibilita a realização de atividades pedagógicas capazes de integrar a tecnologia digital ao currículo.

Incluir a escola na cultura digital é mais do que simplesmente possibilitar o acesso às tecnologias da informação. E necessário criar condiçôes para que as tecnologias digitais façam parte da realidade dos indivíduos e da instituição beneficiada. A inclusão da escola na cultura digital supera o simples acesso a informação devendo preocupar-se em entender os mecanismos que possibilitam a elaboração do conhecimento (HOFFMAN; FAGUNDES, 2008, p. 5). Para tanto, precisa-se analisar o uso

1 Maiores informações sobre o projeto está disponível em: http://www.uca.gov.br/ institucional/projetoPiloto.jsp . Acesso em: 15 maio 2012. 
das tecnologias digitais em contextos profícuos para o aproveitamento de suas potencialidades. Implica aceitar que o aluno tenha o acesso a domínios desconhecidos, colocando-o no centro do processo de ensino-aprendizagem. Fato que exige a visualização de outras organizações espaço-temporais e curriculares.

Tem-se como hipótese que a utilização da tecnologia digital, associada ao desenvolvimento de projetos de iniciação científica, possam gerar tomadas de consciência sobre o papel da mesma no currículo escolar de forma a possibilitar a inclusão digital. Acredita-se que quando, dentro das escolas, há espaços para a reflexão coletiva sobre o projeto político-pedagógico, cada professor é desafiado a pensar a sua área do conhecimento inserida no currículo de modo interdependente, ou seja, em sua dimensão irredutível, complementar e indissociável do conhecimento de cada sujeito.

Neste artigo, apresenta-se como as tecnologias digitais vêm sendo utilizadas durante projetos de iniciação científica. Para tanto, apresenta-se o Web Currículo como um espaço adequado para a integração das tecnologias digitais no contexto escolar. Na sequência, se definem os projetos de iniciação científica relacionando suas etapas de desenvolvimento com a construção dos sistemas conceituais, procedimentais e atitudinais dos alunos. Descreve-se o contexto do estudo, apresentando a observação participante e o estudo de caso como as metodologias utilizadas na análise dos dados. Por fim, são feitas considerações sobre as contribuições da tecnologia digital para o desenvolvimento dos projetos de iniciação científica.

\section{Web Currículo: espaços para integrar a tecnologia digital ao contexto escolar}

O modelo curricular para a era digital deve ser capaz de atender a estrutura informal da comunicação global numa sociedade em rede. A expectativa é de que a escola seja capaz de atender 
as necessidades da sociedade do conhecimento, expressando inovações e transformações dentro do próprio ambiente escolar. Tais transformações exigem reflexões a respeito do currículo, das metodologias, enfim das propostas pedagógicas desenvolvidas.

Nesse sentido, a integração das tecnologias ao currículo exige que o mesmo seja entendido como um processo, como uma práxis, capaz de expandir as possibilidades da construção do conhecimento. De acordo com a teoria prática, o currículo consiste numa proposta que pode ser interpretada por professores e alunos de diferentes formas, por isso emerge em contextos e situações específicas (COUTINHO, 2007, p. 5).

Quando as tecnologias digitais deixam de ser utilizadas apenas como ferramentas que dão suporte para o desenvolvimento da aprendizagem, elas assumem o papel de "próteses ou amplificadores cognitivos” (COLL; MONEREO, 2010, p. 50). Constituem-se como instrumentos capazes de ampliar cognição humana auxiliando na elaboração dos sistemas de significação dos sujeitos (FAGUNDES, 2012). Nessas condições, as tecnologias digitais se tornam estruturantes do currículo porque são utilizadas como instrumentos de mediação do conhecimento. O processo evolutivo que visa à integração das tecnologias digitais ao currículo está sendo denominado de Web Currículo, nele, "tecnologias e currículo passam a se imbricar de tal modo que as interferências mútuas levam a ressignificar o currículo e a tecnologia” (ALMEIDA; SILVA, 2011, p. 4)

Assis et al. (2010) apresentam como fontes geradoras do Web Currículo: a interação, o atividade cooperativa e o protagonismo de todos atores. Este modelo de currículo foca na aprendizagem e se propõe a superar as metodologias que priorizam o ensino através da transmissão de conhecimento. Seus estudos, em relação às estratégias pedagógicas e metodológicas indicam a necessidade de o projeto pedagógico estabelecer situações que permitam a elaboração dos conhecimentos científicos priorizando a ação dos indivíduos. 
Busca-se, nesta pesquisa, compreender como a utilização das tecnologias digitais associadas a estratégias pedagógicas e metodológicas adotadas no desenvolvimento dos projetos de iniciação científica auxiliam na constituição do Web Currículo, tomando como premissa que a constituição dos sistemas de significação é facilitada quando:

- A organização do currículo parte de questões com significado nas situações cotidianas;

- As tecnologias digitais são utilizadas para produzir e compartilhar informações;

- Existem momentos de cooperação entre alunos e professores;

- As ações do sujeito transcendem os limites da sala de aula.

Desde o princípio, o Web Currículo deve priorizar o processo de aprendizagem, e estar imbuído de cooperação e integração, não apenas das disciplinas, mas de todos os atores envolvidos no contexto escolar. Neste estudo, o termo "Web" representará a possibilidade de produzir e compartilhar o conhecimento no mundo complexo em que vivemos, enquanto que o termo "currículo" representará todas as relações que os sujeitos estabelecem com esse conhecimento. Entende-se que a integração das tecnologias digitais ao currículo escolar está diretamente relacionada aos contextos nos quais é produzida, já que interfere na constituição dos sistemas cognitivos dos alunos.

Portanto, acredita-se que o Web Currículo se constituirá como uma materialização do diálogo incessante que professores e alunos estabelecem com o conhecimento através dos projetos de iniciação científica. Os conteúdos se constituirão como sistemas conceituais, procedimentais e atitudinais, evidenciados durante o desenvolvimento dos projetos.

Considerando que as tecnologias digitais estimulam, tanto individualmente quanto coletivamente, a experimentação, a reflexão e a produção de conhecimentos (COBO; PARDO, 2007), e que a incorporação das tecnologias digitais na educação 
e os efeitos benéficos que ela pode causar são oriundos das suas próprias potencialidades, torna-se fundamental compreender uso efetivo que os professores e alunos fazem dessas tecnologias.

Segundo Coll, Mauri e Onrubia (2010), a inserção das tecnologias digitais na educação pode ocorrer sob três perspectivas:

a) Como conteúdos curriculares - são usadas como objetos de ensino e aprendizagem;

b) Como possibilidade para tornar mais eficientes e produtivos os processos de ensino e aprendizagem - se inseridas em contextos de mudança educacional são capazes de promover inovação.

c) Como elementos capazes de promover novas formas de aprender e ensinar - são usadas como instrumentos de mediação entre os diferentes atores participantes do processo.

As classificações anteriores referentes à inserção das tecnologias digitais no contexto escolar indicam que, para ser capaz de transformar o currículo, sua utilização deve promover mudanças nas formas de ensinar e aprender. O desenvolvimento dos projetos de iniciação científica ressignificam o lugar dos conteúdos e das tecnologias digitais no currículo escolar, na medida em que colocam o aluno no centro do processo de aprendizagem tornando o currículo descentralizado, flexível, transformador e interdisciplinar.

Os projetos de aprendizagem na modalidade de iniciação científica se constituem como uma situação aberta na qual os alunos levantam questões de investigação. Dessa forma, os professores, a princípio, desconhecem os caminhos e conteúdos que serão abordados. Após a escolha das questões, os alunos, em pequenos grupos, buscam, organizam e comparam informações que os auxiliaram na solução dos problemas proposta (COSTA; MAGDALENA, 2008).

Ao estabelecer relações entre as informações obtidas, é gerado conhecimento, compartilhado com auxílio de ambientes virtuais. A socialização dos resultados se constitui como fonte de informação sobre o próprio processo de desenvolvimento 
cognitivo dos sujeitos (FAGUNDES; SATO; MAÇADA, 1999, p. 23). Através do contato com situações que ainda não tenham se confrontado ou que ainda não sejam capazes de explicar, esperase que os sujeitos ativem seus sistemas de significação (PIAGET, 1975). Dessa forma, como proposta metodológica, contempla conteúdos conceituais, procedimentais e atitudinais, os quais estão imbricados na constituição dos sistemas cognitivos dos alunos.

As três grandes categorias de conteúdos apresentadas nos Parâmetros Curriculares Nacionais constituem a espiral evolutiva do conhecimento do aluno que se desenvolve a cada etapa dos projetos de iniciação científica. A produção dos alunos desde as atividades disparadoras contemplam os conteúdos conceituais "[...] ideias, imagens e representação da realidade" (BRASIL, 1997, p. 51). Durante o desenvolvimento do projeto, ao "[...] tomar decisões e realizar uma série de ações, de forma ordenada e não aleatória, para atingir uma meta" (BRASIL, 1997, p. 52) os alunos pesquisadores, com o apoio dos conteúdos procedimentais, aprofundam seu quadro conceitual. Os conteúdos procedimentais estão presentes desde a escrita da justificativa, passando pela seleção e análise das produções referentes ao assunto pesquisado, a escolha da metodologia até o registro da sua própria produção. Da mesma forma, os conteúdos atitudinais permeiam o processo já que os valores e atitudes se tornam necessários para o bom andamento do trabalho em equipe. Os progressos na interação e cooperação ficam evidentes nas rodadas e nas mostras dos trabalhos.

No contexto da pesquisa, os procedimentos ocupam um lugar relevante porque tornam os alunos participantes dos próprios processos de construção e apropriação do conhecimento. Esses consistem em substituir o aprendizado das técnicas pelo desenvolvimento das estratégias de pensamento. Com a mesma importância, os conteúdos atitudinais passam a ser reconhecidos como uma parte constitutiva do currículo. O trabalho em equipe e a divulgação das próprias produções se constituem em espaços de diálogo que exigem dos alunos a interiorização de novas formas 
de comportamento, valorizando o desenvolvimento de atitudes e valores frente ao uso das tecnologias digitais.

Com a perspectiva de compreender como a utilização das tecnologias digitais contribui para a constituição do currículo escolar, analisou-se um contexto no qual o desenvolvimento dos projetos de iniciação científica está associado à disponibilidade dos laptops educacionais distribuídos pelo Projeto UCA. Para tanto, apresentam-se o contexto do estudo, os mecanismos de coleta e análise dos dados e, finalmente através de um estudo de caso, analisa-se o uso da tecnologia digital na constituição dos projetos de iniciação científica.

\section{Contextualização do estudo}

Como fonte de dados empíricos selecionou-se uma das escolas participantes do Projeto UCA. O currículo dessa escola desde o primeiro ano do ensino fundamental se utiliza da metodologia de projetos de iniciação científica. Os projetos de iniciação científica seguem os princípios dos projetos de aprendizagem, enfatizando a autoria dos alunos desde a escolha das questóes. Nessa proposta, os professores assumem o papel de mediadores e não existem conteúdos previamente estabelecidos (FAGUNDES; SATO; MAÇADA, 1999). Diferentes dos projetos de aprendizagem, nos projetos de iniciação científica não se tem a preocupação de registrar as dúvidas temporárias e as certezas provisórias dos alunos como forma de acompanhamento do desenvolvimento conceitual deles. Eles procuram inserir a terminologia da iniciação cientifica: perguntas iniciais e secundárias, justificativa, metodologia e referências (ROSA; FAGUNDES; BASSO, 2012).

Os projetos de iniciação científica podem ser considerados o elo entre as diferentes áreas do conhecimento e as diferentes séries que compõem o currículo na instituição analisada. Atualmente, no currículo dessa escola, independente da série, há horários 
destinados aos projetos de iniciação científica. Nesses horários, os alunos contam com a presença de professores especialistas de todas as áreas do conhecimento. A garantia de vários especialistas nos horários destinados aos projetos de iniciação científica tem o objetivo de oportunizar momentos de orientação interdisciplinar e de garantir um número pequeno de orientandos por professor.

Organizados em equipes de trabalho, os docentes participam de reuniões semanais nas quais há professores representantes de todas as áreas do conhecimento. Para a constituição dessas equipes foi considerada a faixa etária dos alunos atendidos. Embora cada uma das equipes possua um nome específico, neste estudo, utilizaram-se letras maiúsculas para a identificação das mesmas: (a) Equipe A: $1^{\mathrm{O}}$ ao $5^{\circ}$ ano do Ensino Fundamental; (b) Equipe B: $6^{\circ}$ e $7^{\circ}$ anos do Ensino Fundamental; (c) Equipe $C$ : $8^{\circ}$ e $9^{\circ}$ anos do Fundamental; (d) Equipe D: $1^{\circ}, 2^{\circ}$ e $3^{\circ}$ anos do Ensino Médio; (e) Equipe $E^{1 ; 2}$ :Educação de Jovens e Adultos do Ensino Fundamental e Médio.

No ano de 2010, a instituição recebeu os laptops educacionais da primeira fase do Projeto UCA. As combinações quanto à distribuição e uso dos mesmos foram feitas dentro das equipes de trabalho, assim como o planejamento e as estratégias de avaliação também são desenvolvidos a partir das decisões tomadas em conjunto pelos professores. Com o objetivo de compreender o uso que tem sido feito dos laptops educacionais nos projetos de iniciação científica decidiu-se acompanhar uma dessas equipes. No próximo texto apresentam-se os critérios utilizados para a seleção da Equipe C como fonte de dados, bem como a metodologia utilizada na análise.

2 Optamos por utilizar a terminologia atual, ou seja, anos no lugar de séries. No entanto, cabe ressaltar que somente em 2013 existirão turmas de $7^{\circ}$ ano no Ensino Fundamental. No ano de 2012 a equipe $\mathrm{C}$ ainda era composta por turmas de sétima e oitavas séries. 


\section{Coleta e análise dos dados}

Neste estudo, serão apresentados dados coletados junto a Equipe C, composta por alunos do $8^{\circ}$ e $9^{\circ}$ anos do Ensino Fundamental. Os dados apresentados, neste estudo, são de natureza qualitativa e foram coletados através de observação participante (BOGDAN; BICKLEN, 1994). A fim de identificar as perspectivas de uso dos laptops educacionais no contexto da iniciação científica, foram produzidos vídeos os quais estão em fase de transcrição. Acompanharam-se, durante o segundo semestre de 2011, dois grupos de alunos em dois encontros semanais de uma hora e meia cada, destinados ao desenvolvimento dos projetos de iniciação científica.

O estudo de caso seguiu as orientaçóes propostas por Yin (2010). Inicialmente estruturou-se a Tabela 1 , na qual foram registradas as tecnologias digitais e seu uso feito pelos professores. Na sequência fez-se um levantamento do número de mensagens trocadas entre os professores identificando em quais contextos esse recurso foi utilizado. Com o auxílio do Software $\mathrm{Nvivo}^{3}$, foram feitas transcriçôes de quatro vídeos relativos às reuniôes de planejamento dos professores referentes aos meses de maio e junho de 2011. Selecionou-se, dentre as transcrições, falas que evidenciassem as perspectivas dos professores em relação à utilização das tecnologias digitais. Essas falas foram indicadas por letras maiúsculas $\mathrm{A}$ (alunos) e $\mathrm{P}$ (professores) e indexadas com números, a fim de garantir a não identificação dos mesmos. Finalmente, foram analisadas as Wikis produzidas por alunos e professores relacionando as falas com as estratégias de uso delas.

Como pode ser observado a Tabela 1 , abaixo, indica que os professores utilizam de recursos variados que superam a simples produção de materiais ou pesquisa de informaçôes relativas aos conteúdos de suas disciplinas. Em geral os materiais produzidos foram compartilhados, ora entre professores, ora entre alunos,

3 O Nvivo é um software de análise qualitativa e quantitativa de dados. Ele facilita o armazenamento e a categorização dos dados. 
utilizando-se recursos da Web 2.0. O quadro indica a preocupação dos professores em compartilhar a informação em tempos e espaços diferentes, utilizando mais de um recurso para isso (Google Docs, Slide Share, Google Grupos, entre outros). Isso evidencia que a utilização das tecnologias digitais tornou mais eficiente e produtivo o processo de ensino e aprendizagem conforme os níveis (b) e (c) indicados propostos por Coll, Monereo e Onrúbia (2010).

Tabela 1: Tecnologias digitais utilizados pelos professores no contexto escolar

\begin{tabular}{|c|c|}
\hline Tecnologias Digitais & Como foram utilizadas \\
\hline $\begin{array}{l}\text { Editores de texto, } \\
\text { software para cria- } \\
\text { ção, edição e exibi- } \\
\text { ção de apresentações } \\
\text { gráficas; planilhas } \\
\text { eletrônicas }\end{array}$ & $\begin{array}{l}\text { Produzir materiais para alunos; } \\
\text { Elaborar de atas; } \\
\text { Formas de apresentação de conteúdos com } \\
\text { animação para os alunos; } \\
\text { Apresentar os resultados dos projetos } \\
\text { desenvolvidos; } \\
\text { Organizar e divulgar os locais de realização } \\
\text { das oficinas e mostras de projetos desenvol- } \\
\text { vidos pelos alunos. }\end{array}$ \\
\hline $\begin{array}{l}\text { Câmeras fotográficas } \\
\text { e filmadoras digitais }\end{array}$ & $\begin{array}{l}\text { Registrar as apresentações dos alunos nas } \\
\text { mostras de iniciação científica; } \\
\text { Registrar saídas de campo. }\end{array}$ \\
\hline Editores de vídeo & $\begin{array}{l}\text { Organizar o material produzido para com- } \\
\text { partilhar via web. }\end{array}$ \\
\hline Softwar Cmap Tools & Produzir o mapa conceitual do projeto. \\
\hline Google Grupos & $\begin{array}{l}\text { Planejar saídas de campo, reuniôes com pais; } \\
\text { Compartilhar materiais, atas, imagens, que } \\
\text { exigissem algum tipo de sigilo; } \\
\text { Discutir situaçôes específicas da série. }\end{array}$ \\
\hline $\begin{array}{l}\text { Repositórios virtuais } \\
\text { de vídeos e imagens }\end{array}$ & $\begin{array}{l}\text { Compartilhar informações com alunos e } \\
\text { professores }\end{array}$ \\
\hline Google Docs & $\begin{array}{l}\text { Elaboração da estrutura de desenvolvimento } \\
\text { do projeto de iniciação científica; } \\
\text { Elaboração de instrumentos de avaliação; } \\
\text { Elaboração de pareceres. }\end{array}$ \\
\hline
\end{tabular}




\begin{tabular}{ll}
\hline Blogs & $\begin{array}{l}\text { Compartilhar informações com alunos, } \\
\text { disponibilizando documentos, vídeos, ima- } \\
\text { gens, sons... }\end{array}$ \\
\hline Wikis & $\begin{array}{l}\text { Compartilhar informações com alunos, } \\
\text { disponibilizando documentos, vídeos, ima- } \\
\text { gens, sons... }\end{array}$ \\
\hline
\end{tabular}

Há que ser destacado que utilização do Google Grupos funcionou muito como uma lista de discussão. Através desse recurso, durante o período de maio a dezembro, foram trocadas 171 mensagens. Outro aspecto a ser considerado é a utilização de Wikis pelos professores. Dos 24 professores que compõem a equipe, 20 criaram Wikis individuais, sendo que muitas dessas serviram como fonte de registro e compartilhamento de materiais e informações tanto entre os professores quanto entre os alunos. Como pode ser visualizado nas Figuras 1 e 2:

Figura 1: Wiki de professor fornecendo orientações sobre o desenvolvimento dos projetos e link para a página dos colegas

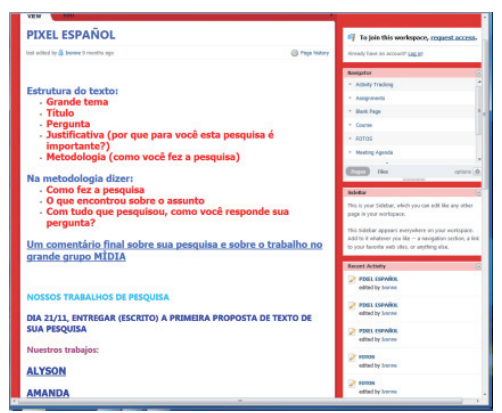

Figura 2: Wiki de professor registrando os materiais produçốes da oficina sobre teatro e cinema

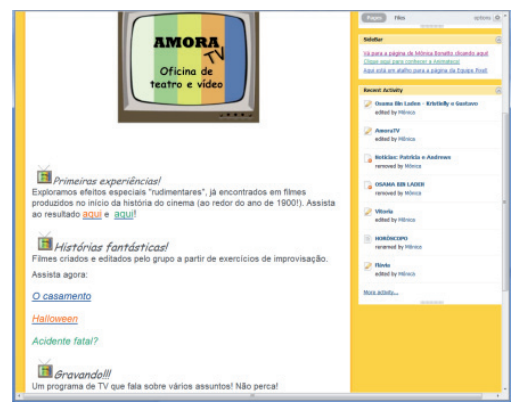

Fonte figura 1: http://pixel70espanol2011.pbworks.com/w/page/47349890/ PIXEL\%20ESPA\%C3\%91OL Acesso em 22 mar 2013.

Fonte figura 2: http://amoratv.pbworks.com/w/page/38252361/AmoraTV Acesso em 22 mar 2013. 
O objetivo do grupo de professores em utilizar as Wikis para registro, acompanhamento e divulgação dos projetos de iniciação científica fica muito bem expresso nas seguintes falas:

$\mathrm{P}_{1:}$ "Nós conversamos na segunda-feira sobre uma forma de registro bacana, que permitisse que todo mundo soubesse $o$ que os colegas estão fazendo certo. Foi sugerido e-mail, mas daí nós pensamos que vai ter que mandar e-mail para todo mundo. Teve várias sugestôes até que alguém falou numa Wiki. A professora $\mathrm{P}_{4}$ já tinha uma Wiki criada. Vocês não publicaram na Wiki, mas vários outros grupos usaram e tem seus trabalhos registrados. Vocês também vão poder, em algum momento, dar uma pesquisada para ver o que os colegas fizeram."

$\mathrm{P}_{2:}$ "Então qual é a nossa proposta? É que tudo o que a gente produzir fique registrado aqui na Pbworks, nessa nossa Wiki: as produções individuais nas páginas de vocês, as produções gerais na página inicial (aquela que abre com o nome de todo mundo). Eu acho que esse é um jeito muito bacana da gente trocar e saber o que os colegas estão fazendo."

$\mathrm{P}_{3:}$ "A ideia é a seguinte: vocês tem e nós vamos usar bastante o UCA nesses projetos! Toda aula vocês vão publicar alguma coisa na internet e a ideia é que também consigam visitar sites dos colegas para dar opinióes e a gente vai fazer a mesma coisa."

As falas dos professores $\mathrm{P}_{1}, \mathrm{P}_{2}$ e $\mathrm{P}_{3}$ valorizam a troca de informações possibilitada pela publicação das pesquisas em Wikis. Destacam que outros grupos participantes do projeto já faziam uso desse recurso e têm como meta que a produção dos alunos sirva como fonte de consulta. Esse desejo de compartilhar as informações certamente transforma as Wikis em espaços colaborativos, os quais, associados à possibilidade de serem tecidos comentários contendo sugestóes e encaminhamentos relativos a continuidade de pesquisa, mostra que além de colaboração os professores desejam estabelecer a cooperação entre os membros que compõem o grupo de pesquisa.

Nessas situações, os alunos-pesquisadores apresentam a produção realizada durante a investigação utilizando diversos recursos como textos, vídeos, editores de apresentação, mapas 
conceituais, peças teatrais, enfim, recursos condizentes com o assunto e os temas pesquisados. As Figuras 3 e 4 ilustram essa forma de registro.

Figura 3: Wiki de aluno apresentando a primeira versão do mapa conceitual sobre seu tema de pesquisa

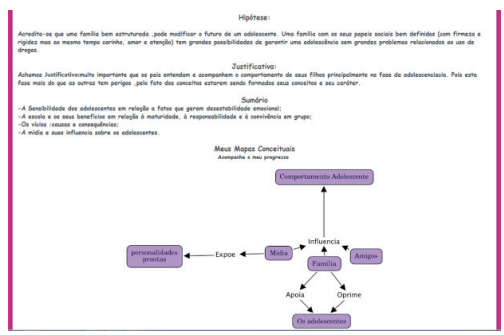

Figura 4: Wiki de aluno na qual foi acoplado um vídeo sobre o tema de pesquisa, abaixo orientações feitas pelo professor sobre como proceder.

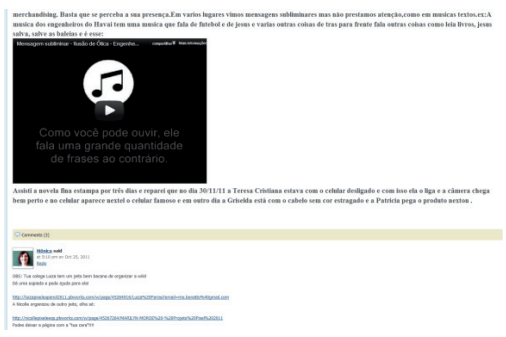

Fonte figura 3: http://pesquisasdapaolaaaa.pbworks.com/w/page/30921721/ FrontPage Acesso em 22 mar 2013.

Fonte figura 4: http://chpixelesp.pbworks.com/w/page/45266394/Christian\%20Pereira Acesso em 22 mar 2013.

Enfim, a forma como as tecnologias digitais tem sido utilizadas nos projetos de iniciação científica permitem "organizar estas informações de forma inteligente e prática, avaliando sua importância e necessidade, descobrindo, com base nestas, como construir ou (re) construir um novo conhecimento" (SILVA, 2005 p. 19). As páginas construídas ao longo do projeto apresentam diferentes níveis de construção. A cada etapa de desenvolvimento vão surgindo elaborações cada vez mais complexas evidenciadas pelo conhecimento ali registrado. Acompanhar esses progressos sem os recursos digitais seria muito mais complexo.

\section{Considerações finais}

Este estudo preliminar indica que a partir dos projetos de aprendizagem na modalidade iniciação científica existe a 
possibilidade de emergir um modelo de currículo em rede, Web Currículo. Isso porque o uso das tecnologias digitais, no contexto analisado, tem provocado alterações no processo de aprendizagem ressignificando os papéis dos alunos e dos professores.

Observou-se que dentre seus objetivos os professores pretendem aproveitar os recursos dos laptops educacionais para compartilhar o conhecimento produzido entre os alunos, bem como, para planejar e enriquecer as atividades de sala de aula. A diversidade de tecnologias digitais utilizadas pelos professores indica que eles estão se sentindo motivados e buscando se apropriar desses recursos. As listas de discussão estão constituindo-se como um importante meio de comunicação entre os professores. As Wikis, além de fornecerem suporte para registro e divulgação dos conhecimentos produzidos pelos alunos, têm servido como espaço de interação entre alunos e professores.

Dessa forma, as tecnologias digitais estão ampliando as possibilidades de produção de conhecimento e já incorporaram novas formas de registro da informação, contemplando a produção de imagens, vídeos, links e sons aos trabalhos produzidos tanto por alunos quanto por professores. As condutas dos professores e alunos, em relação às tecnologias digitais, observadas neste estudo, indicam que as mesmas têm sido utilizadas como recursos que valorizam autonomia, criatividade e curiosidade.

Em estudos futuros, se pretende analisar os materiais produzidos pelos alunos com o objetivo de compreender como se dão as elaborações conceituais, procedimentais e atitudinais durante os projetos de iniciação científica. Acredita-se que a principal contribuição deste trabalho será fornecer subsídios para instituições que se sintam desafiadas a superar um modelo empirista de ensino, não apenas dizendo por que fazê-lo, mas fundamentalmente fornecendo indicadores de como fazê-lo. 


\section{Referências}

ASSIS, Maria Paulina de. Web curriculum - The Integration of ICT in Education. In: Anais -E-Societ 2010. IADIS - International Conference of the Information Society. Porto, 2010

ALMEIDA, Maria Elizabeth B. de; SILVA, Maria da Graça Moreira da. Currículo, tecnologia e cultura digital: espaços e tempos de web currículo Revista e-curriculum. São Paulo, v. 7 n. 1 Abril/2011. Disponível em: $<$ http://revistas.pucsp.br/index.php/curriculum>. Acesso: 10 jun. 2011

BOGDAN, Roberto C.; BICKLEN, Sari Knopp. Investigação qualitativa em educação. Porto: Porto Editora, 1994

BRASIL. Secretaria de Educação Fundamental. Parâmetros curriculares nacionais: introdução aos parâmetros curriculares nacionais. Secretaria de Educação Fundamental. Brasília: MEC/SEF,1997.

COBO, Romaní Cristóbal; PARDO, Kuklinski, Hugo. Planeta Web 2.0. Inteligencia colectivao medios fast food. Grup de Recerca d'Interaccions Digitals, Universitat de Vic. Flacso México. Barcelona/México DF, 2007.

COLL, Cesar; MAURI, Tereza; ONRUBIA, Javier. A incorporação das tecnologias da informação e comunicação na educação. In: COLL, Cesar; MONEREO, Carles. Psicologia da educação virtual: aprender e ensinar com as tecnologias da informação e da comunicação. Porto Alegre: Artmed, 2010.

COLL, Cesar; MONEREO, Carles. Psicologia da educação virtual: aprender e ensinar com as tecnologias da informação e da comunicação. Porto Alegre: Artmed, 2010.

COSTA, Iris Elisabeth Tempel; MAGDALENA, Beatriz Corso. Revisitando os Projetos de Aprendizagem, em tempos de web 2.0. In: Anais, XIX Simpósio Brasileiro de Informática na Educação. Fortaleza/ CE, Brasil

COUTINHO, Clara Pereira. Tecnologia educativa e currículo: caminhos que se cruzam ou se bifurcam? In: TEIAS: Rio de Janeiro, ano 8, n. 1516, jan./dez., 2007.

FAGUNDES, Lea da Cruz. Educação Integral e Educação Digital: Construindo um Novo Paradigma para a Educação Brasileira. In: IV 
Seminário Nacional de Educação Integral: Contribuições do Programa Mais Educação, 2012 (mimeo).

FAGUNDES, Lea da Cruz; SATO, Luciane Sayuri; MAÇADA, Débora. Aprendizes do futuro: as inovações começaram. Coleção: Informática para a mudança na Educação. MEC/PROINFO, Brasília, 1999.

HOFFMMAN, Daniela; FAGUNDES, Lea da Cruz. Cultura Digital na Escola ou Escola na Cultura Digital? In: RENOTE. Revista de Novas Tecnologias na Educação, v. 6 n. 1, Julho, 2008.

PIAGET, Jean. A equilibração das estruturas cognitivas: problema central do desenvolvimento. Rio de Janeiro: Zahar, 1975.

ROSA, Marlusa Benedetti da; FAGUNDES, Lea da Cruz; BASSO, Marcus. Vinicius. De Azevedo. Alterações no contexto escolar: rumo ao desenvolvimento de um Web Currículo. In: RENOTE, v. 10, n. 1, 2012

SILVA, Maristela. Projetos de Aprendizagem @ Tecnologias. Transformações. Escola Dissertação apresentada ao curso de Pós-Graduação em Educação da Universidade Federal do Rio Grande do Sul, 2005.

YIN, Robert. Estudo de caso: planejamento e métodos. 4. ed. Porto Alegre: Bookman, 2010. 